\title{
The Impact of Human Resources Policies on Organizational Commitment: The Mediating Role of Psychological Contract (Applied Study: Alexandria Water Company)
}

\author{
Doaa Sabry Abdel-Nasr Nassar \\ Arab Academy for Science and Technology, Alexandria, Egypt \\ Email: doaanassar37@gmail.com
}

How to cite this paper: Nassar, D.S.A.-N. (2021) The Impact of Human Resources Policies on Organizational Commitment: The Mediating Role of Psychological Contract (Applied Study: Alexandria Water Company). Open Access Library Journal, 8: e7249.

https://doi.org/10.4236/oalib.1107249

Received: February 15, 2021

Accepted: March 28, 2021

Published: March 31, 2021

Copyright $\odot 2021$ by author(s) and Open Access Library Inc.

This work is licensed under the Creative Commons Attribution International License (CC BY 4.0).

http://creativecommons.org/licenses/by/4.0/ (c) (i) Open Access

\begin{abstract}
The purpose of paper is to explore the role of the psychological contract as a mediating variable between human resources policies and organizational commitment in these organizations, also the paper aims to review the concept of psychological contract, and the different practices of human resources policies and organizational commitment in service business organizations. In order to achieve the purposes of the study, researcher adopted a descriptive analytical method, researcher depended on questionnaire as the main tool for collecting data; where (400) questionnaires were distributed, and (331) questionnaires were retrieved for analysis, rating $(82.75 \%)$ of the distributed questionnaires. Analyzing data was conducted using a set of statistical methods including Cronbach's alpha along with a normality test, standard deviation, exploratory factor analysis, confirmatory factor analysis, simple and multiple linear regression using SPSS-V26 and AMOS-V25. The study reached a set of results, the most important of which are: 1) There is a statistically impact at significant level $(\alpha \leq 0.05)$ of human resources policies on organizational commitment through the psychological contract as a mediating variable in Alexandria Water Company in Egypt. 2) There is a significant correlation between psychological contract and human resources policies, also there is a significant correlation between human resources policies and organizational commitment, and finally there is a significant correlation between psychological contract and organizational commitment. The study reached a set of recommendations, the most important of which are: 1) Managers and firm owners should pay attention to the psychological contract, as it greatly contributes to forming employees' image about the company competencies. 2) Managers should minimize perceptions of psy-
\end{abstract}


chological contract violation through human resource policies that foster promises, acceptance, and reliance.

\section{Subject Areas}

Human Resource Management

\section{Keywords}

Psychological Contract, Organizational Commitment, Human Resources Policies

\section{Introduction}

Human Resources management is one of the most important resources of the organization and one of the most important assets owned by organizations. It is not possible to achieve goals, without Human Resources [1].

Human resource management is one of the main organizational factors influencing employment relationship at the organization level ( $\mathrm{Lv}$ and $\mathrm{Xu}, 2016)$ [2], since employees choose to join an organization when they think that it seems to fulfill their needs (Aries, 2013) [3]. Likewise, the decision to remain in an organization depends upon the degree to which the expected utility of remaining at the job exceeds the alternative utility plus the cost of change (Bellou, 2007) [4].

Human Resource practice plays a very important role on employee attitudes and performance specially when the organization fulfills its obligations towards employees, which reflects in shaping what has been called in the literature "psychological contracts" (Restubog et al., 2015) [5]. Psychological contracts are defined as "individual beliefs, shaped by the organization, regarding terms of an exchange agreement between individuals and their organization (Antony, 2013) [6].

Organizational commitment is widely described in the management and behavioural science literature as a key factor in the relationship between individuals and organizations. Adekola (2012) [7] described organizational commitment as the factor that promotes the attachment of the individual to the organization. It's probably that, high levels of effort exerted by employees with high levels of organizational commitment lead to higher levels of performance and effectiveness at both the individual and the organizational level (Loan, 2020) [8].

The issues of the psychological contract, human resource management policies, and organizational commitment have received the attention of many researchers, but most previous studies have dealt with these variables separately or studied the relation between only two variables. Numerous studies have examined the link between human resource practices and psychological contract. The formation of the "exchange" relationship begins during the recruitment and 
selection process and continues throughout the employee's tenure with an organisation (Abdel-Rahman, 2005) [9]. These studies have shown how recruitment, training, performance appraisal, compensation and benefits can encourage the formation or elaboration of a psychological contact. A common thread running through the studies examining human resource practices and psychological contract is that an organisation's human resource practices can change the psychological contract status and influence work related outcomes.

Also, previous studies did not link human resource practices with organizational commitment through psychological contract as a mediating variable. In these circumstances, due to the importance of Alexandria Water Company in Egypt and the services it provides to a wide range of citizens, the researcher considered that the psychological contract is a major focus that must be studied, and its great importance on the performance of individuals, and then the organizational performance and organizational commitment of workers, the present study aims to investigate the impact of human resources policies on organizational commitment through the psychological contract as a mediating variable.

The problem of the study is that the psychological contract may positively and negatively affect the formation of the relationship between employees and employers, thus, psychological contract violation may cause non-compliance of employees, which will be reflected in the overall performance of the organization, hence the role of human resources practices in influencing the formation of the psychological contract.

Accordingly, study seeks to test the impact of human resource practices on the organizational commitment of Alexandria Water Company employees, through psychological contract as a mediating variable.

\section{Objectives of the Research}

The objectives of the research are:

1) Reviewing the concept of psychological contract, identifying its types and determining factors, and linking it to human resources policies in business organizations in general, and the Alexandria Water Company in Egypt in particular.

2) A review of the different practices of human resources policies and organizational commitment in service business organizations.

3) Exploring the role of the psychological contract as a mediating variable between human resources policies and organizational commitment in these organizations.

4) Reaching out to a set of recommendations that, if implemented, are expected to lead to the improvement and development of the strategy to preserve the human capital of these organizations.

\section{Research Questions}

Is there a statistical relationship with a significant impact between human re- 
sources policies and the organizational commitment of this type of service organization?

Do human resource management policies affect the psychological contract of Alexandria Water Company?

Does the psychological contract affect the organizational commitment of Alexandria Water Company employees?

Is there an impact of human resources policies on organizational commitment through the psychological contract as a mediating variable?

\section{Research Model}

Figure 1 shows the research model of this study.

\section{Research Hypothesis}

- There is a statistically significant effect of HR policies on psychological contract.

- There is a statistically significant effect of human resources policies on organizational commitment.

- There is a statistically significant effect of the psychological contract on organizational commitment.

- There is a statistically significant effect of human resources policies on organizational commitment through the psychological contract as a mediator variable.

\section{Research Methodology}

The study adopted a descriptive analytical method, the questionnaire was study's main tool for collecting data; where (400) questionnaires were distributed, and (331) questionnaires were retrieved for analysis, the rate was (82.75\%) of the distributed questionnaires. Analyzing data was conducted using a

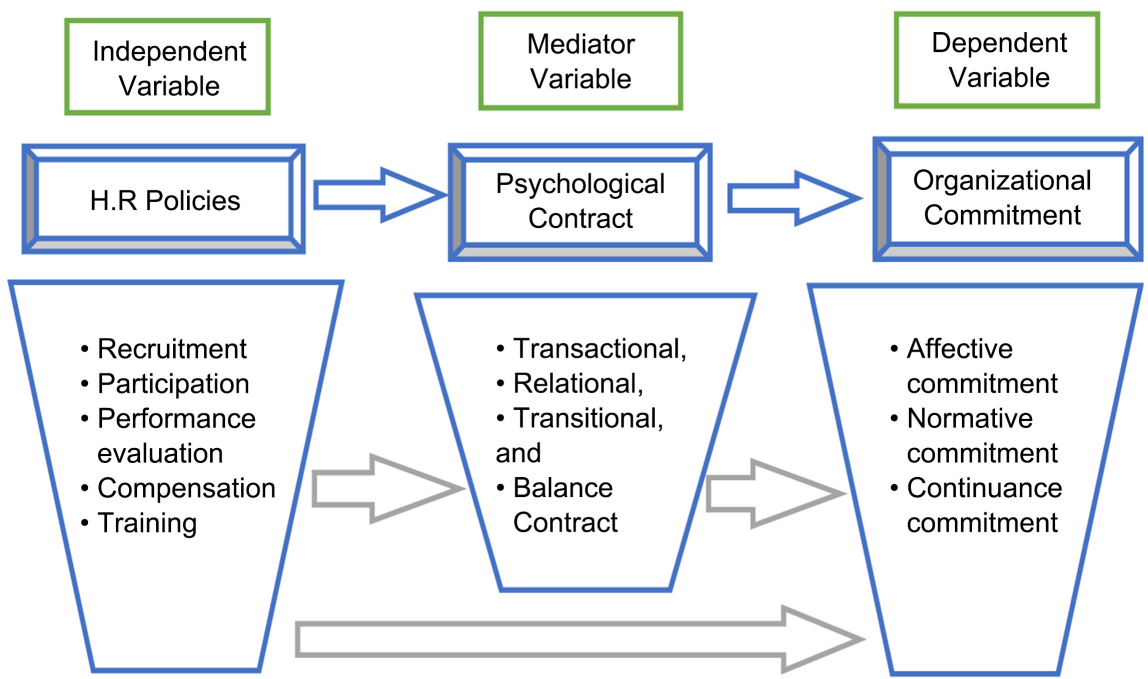

Figure 1. Research model. 
set of statistical methods including Cronbach's alpha along with a normality test, standard deviation, exploratory factor analysis, confirmatory factor analysis, simple and multiple linear regression using SPSS-V26 and AMOS-V25.

In accordance with the objective to review conceptual and empirical research that addresses the role and impact of human resource management in fostering psychological contracts, researcher focused on theoretical and empirical studies based on their titles and abstract. Papers that specifically addressed human resource practices and psychological contract were chosen for the review.

\subsection{Study Tool}

The study relied on the questionnaire as the performance of the main study. A questionnaire was prepared on "the impact of the psychological contract as a mediating variable between human resources policies and organizational commitment" applied study Alexandria water company in Egypt.

The questionnaire consists of:

1) Part 1: personal data.

2) Part Two: variables dimensions and items.

The following table shows the sources of the questionnaire questions that were developed from previous studies to answer the study questions.

\subsection{Pilot Study}

For the purposes of testing the validity and reliability of the questionnaire, the researcher distributed a survey sample of 40 questionnaires.

The reliability of the study questionnaire was verified by Cronbach's Alpha coefficient, and the results showed the Cronbach Alpha coefficient (0.924) which is a statistically acceptable level as long as it is greater than (0.6).

\section{Hypothesis Testing Results}

\subsection{First Main Hypothesis Test}

To test the first main hypothesis, the null hypothesis was developed which is that there is no significant statistical effect of human resources policies on the psychological contract of employees of the drinking water company, and to verify the validity of the hypothesis, the simple regression test was used between human resources policies as an independent variable, and the psychological contract is a dependent variable, Table 1 shows the results as follows:

It is evident from Table 2 that the statistical value $(\mathrm{T})$ is (3.316) with a statistical significance level less than $5 \%(0.05 \mathrm{p} \leq)$, We reject the null hypothesis, which indicates that there is a statistically significant impact of human resources policies on the psychological contract, and accordingly we conclude that there is an impact A statistically significant of human resources policies on the psychological contract.

Regression equation is: $\quad \mathrm{y}=\propto+\mathrm{B} x$

psychological contract $=2.059+0.144$ H.R Policies. 
Table 1. Impact of human resources policies on psychological contract.

\begin{tabular}{cccccc}
\hline & B & Standard Error & Beta & T & Sig \\
\hline Constant & 2.059 & 0.103 & & 19.942 & 0.000 \\
HR Policies & 0.144 & 0.044 & 0.18 & 3.316 & 0.001 \\
\hline
\end{tabular}

Table 2. Questionnaire items source.

\begin{tabular}{ccc}
\hline Variable & Items No & Source \\
\hline Human Resource Practices & 35 & $($ Al-Mabrouk, 2017) $[10]$ \\
Psychological Contract & 30 & $($ Abrar, 2019) $[11]$ \\
Organizational Commitment & 23 & $($ Abrar, 2019) $[11]$ \\
\hline
\end{tabular}

\subsection{Sub-Hypotheses Test for the First Main Hypothesis}

To test the sub-hypotheses, the null hypothesis was developed that is represented by the absence of a statistically significant impact from the dimensions of human resources policies (recruitment, participation, performance evaluation, compensation, training) on the psychological contract, and to verify the validity of the hypothesis, the multiple regression test was used between the dimensions of resource policies (recruitment, participation, performance evaluation, compensation, training) as independent variables and between the psychological contract as a dependent variable, Table 3 shows the results as follows:

From Table 3 it becomes clear that the statistical value $(\mathrm{T})$ of the dimensions of human resources policies (recruitment, participation, performance evaluation, compensation, training) amounted to $(2.296,2.338,4.091,4.658,2.754)$, respectively, with a level of statistical significance less than $5 \%$. Amounted to $(0.022,0.02,0.000,0.000,0.006)$ It is evident that there is a statistically significant effect from all dimensions of human resources policies (recruitment, participation, performance evaluation, compensation, training) on the psychological contract as all values of the significance level coefficients (Sig) are less than 0.05 , which indicates the presence of a significant effect. A statistic of all dimensions of human resources policies (employment, participation, performance evaluation, compensation, training) on the psychological contract.

\subsection{Second Main Hypothesis Test}

To test the second main hypothesis, the null hypothesis was developed which is that there is no significant statistical effect of human resources policies on the organizational commitment of the employees of the drinking water company. Table 4 shows the results as follows:

Regression equation is: $\quad \mathrm{y}=\propto+\mathrm{B} x$

psychological contract $=2.04+0.151$ organizational commitment.

It is evident from Table 4 that the statistical value $(\mathrm{T})$ is (3.262) with a statis- 
tical significance level less than $5 \%$, which indicates that there is a statistically significant impact of human resources policies on organizational commitment, and accordingly, there is no statistically significant impact of human resources policies on organizational commitment, and accordingly we conclude that there is a statistically significant impact from resource policies has an organizational commitment.

\subsection{Sub-Hypotheses Test for the Second Main Hypothesis}

In order to test the sub-hypotheses, the null hypothesis was developed that is the absence of a statistically significant impact from the dimensions of human resources policies (recruitment, participation, performance evaluation, compensation, training) on organizational commitment, and to verify the validity of the hypothesis, the multiple regression test was used between the dimensions of resource policies Human rights (recruitment, participation, performance evaluation, compensation, training) as independent variables and between organizational commitment as a dependent variable, and Table 5 illustrates the results as follows:

Table 3. Impact of human resources policies dimensions on psychological contract.

\begin{tabular}{cccccc}
\hline H.R policies Dimensions & B & Standard Error & Beta & T & Sig \\
\hline Recruitment & 0.085 & 0.037 & 0.118 & 2.296 & 0.022 \\
Participation & 0.090 & 0.038 & 0.127 & 2.338 & 0.020 \\
Performance evaluation & 0.156 & 0.038 & 0.218 & 4.091 & 0.000 \\
Compensation & 0.183 & 0.039 & 0.250 & 4.658 & 0.000 \\
Training & 0.096 & 0.035 & 0.134 & 2.754 & 0.006 \\
\hline
\end{tabular}

Table 4. Impact of human resources policies on organizational commitment.

\begin{tabular}{cccccc}
\hline & B & Standard Error & Beta & T & Sig \\
\hline Constant & 2.04 & 0.109 & & 18.643 & 0.000 \\
H.R Policies & 0.151 & 0.046 & 0.177 & 3.262 & 0.001 \\
\hline
\end{tabular}

Table 5. Impact of human resources dimensions policies on organizational commitment.

\begin{tabular}{cccccc}
\hline H.R policies Dimensions & Standard Error & Beta & T & Sig & B \\
\hline Recruitment & 0.016 & 0.036 & 0.021 & 0.450 & 0.653 \\
Participation & 0.066 & 0.037 & 0.088 & 1.796 & 0.073 \\
Performance evaluation & 0.244 & 0.037 & 0.322 & 6.652 & 0.000 \\
Compensation & 0.157 & 0.038 & 0.202 & 4.135 & 0.000 \\
Training & 0.242 & 0.034 & 0.317 & 7.187 & 0.000
\end{tabular}


From Table 5 it becomes clear that the statistical value $(\mathrm{T})$ of the dimensions of human resources policies (recruitment, participation, performance evaluation, compensation, training) are $(0.45,1.796,6.652,4.135$, and 7.187$)$, respectively, with a level of statistical significance amounting to $(0.653,0.073,0.000$, $0.000,0.000)$, and it is evident that there is a statistically significant impact from most dimensions of human resources policies, where there is a statistically significant effect (performance evaluation, compensation, training) on organizational commitment as the values of the significance level coefficients (Sig) For these variables less than 0.05 , while there is no statistically significant effect of (recruitment, participation) on organizational commitment as the values of the significance level coefficients (Sig) for these variables are greater than 0.05 .

We conclude from this that there is a statistically significant impact of human resources policies on organizational commitment, which reflects the impact and role of human resources policies on achieving organizational commitment of company employees.

\subsection{Third Main Hypothesis}

To test the third main hypothesis, the null hypothesis was developed, which is the absence of a statistically significant relationship between human resources policies and organizational commitment through the psychological contract as an intermediate variable.

And to verify the validity of the hypothesis and study the extent of a total or partial relationship, the Path Analysis test was used, using the Amos 26 program and Figure 2, Table 6 illustrate that.

1) Observed Exogenous Variables: The independent variable includes human resource practices.

2) Observed Endogenous Variables: The dependent variable includes organizational commitment, and the mediating variable includes the psychological contract.

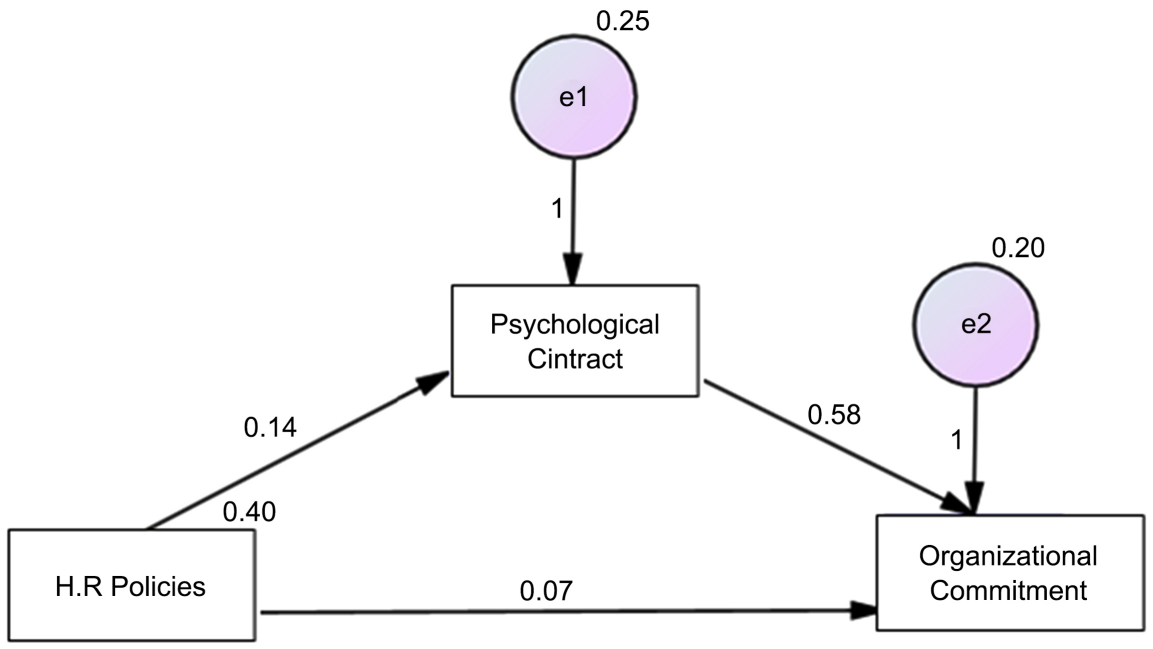

Figure 2. Mediator path. 
Table 6. Variables paths.

\begin{tabular}{ccccccccc}
\hline \multicolumn{1}{r}{ Path } & & Estimate & Standard Eroor & Critical Ratio & Sig (P) & Sig \\
\hline H.R & $\rightarrow$ & Psy Contract & 0.144 & 0.043 & 3.321 & 0.001 & Sig \\
Psycological Contract & $\rightarrow$ & O Commintment & 0.577 & 0.049 & 11.792 & 0.001 & Insig \\
H.R & $\rightarrow$ & O Commintment & 0.067 & 0.039 & 1.711 & 0.087 & Insig \\
\hline
\end{tabular}

3) Unobserved Exogenous Variables: Measurement errors of the dimensions of the dependent variable include organizational commitment, and the mediating variable, the psychological contract.

From the previous table and figure, it is clear that at a level of significance 0.05 , there is a statistically significant effect of Human Resources path on the psychological contract with a factor of 0.14 , and the psychological contract Path on organizational commitment with an impact factor of 0.57 , as the value of the level of significance for both path is 0.000 , which is less than 0.05 While there is no statistically significant impact of the human resources bath on organizational commitment, as the value of the level of significance is equivalent to 0.087 , i.e. greater than 0.05 .

\section{Model Fit Summary}

\section{Table 7 shows the following:}

Chi-square (X2): tests the null hypothesis of this test is, the model fits the model is better when it has a small value, whereas this model value is 0.000 , model is perfect fit.

Goodness of Fit Index (GFI): purpose of computing GFI in the case of maximum likelihood estimation, GFI is less than or equal to 1 . A value of 1 indicates a perfect fit.

Whereas this model value is 1 , model is perfect fit.

The Comparative Fit Index (CFI): parameter estimate for the model being evaluated, CFI is truncated to fall in the range from 0 to 1 . CFI values close to 1 indicate a very good fit. Whereas this model value is 1 , model is fit.

The square root of the mean squares of remainder (RMR): It is an indicator of the estimated amount, and the model is better when it has a small value, whereas this model value is 1 , model is fit.

Root Mean Square Error of Approximation (RMSEA): Independent model value is 0.368 , the value of the RMSEA of about 0.05 or less would indicate a close fit of the model in relation to the degrees of freedom, but for the independent model, it accepted according to Independent model.

Based on the previous results and after checking the model test and all the criteria for judging model goodness, and accordingly, the relationship to the mediating variable, which is the psychological contract, is a holistic relationship and not a partial one, as there is no significance for the relationship between human resources on the organizational commitment of the existence of the psychological contract, which means that the psychological contract A necessary condition for the impact of human resource policies on organizational commitment. 
Table 7. Mediating model fit indices.

\begin{tabular}{cc}
\hline Item & Index \\
\hline Chi Square X & 0.000 \\
Goodness of Fit Index (GFI) & 1 \\
The Comparative Fit Index (CFI) & 1 \\
Root Mean Square Residual (RMR) & 0.000 \\
Root Mean Square Error of Approximation (RMSE) & 0.368 \\
\hline
\end{tabular}

\section{Results}

- There is a statistically significant impact of human resources policies on the psychological contract, which explains the effect of various human resources policies in forming the psychological contract elements within the minds of the parties to the contract, whether they are company owners or employees.

- There is a statistically significant impact of the dimensions of human resources policies (recruitment, participation, performance evaluation, compensation, training) on the psychological contract, which explains the strong impact of multiple human resources practices in forming a strong psychological contract in worker minds, which reflects workers great expectations, also owners' hope about what workers will introduce.

- There is a statistically significant impact of human resources policies on organizational commitment, which explains the effect of multiple and effective human resources policies in achieving organizational commitment of company employees.

- There is a statistically significant impact of human resources policies on organizational commitment through the psychological contract as a mediator variable, and the holistic impact of psychological contract, which means that it will be no significant effect of human resources policies on the organizational commitment without psychological contract, which means the psychological contract is a necessary condition in order to have an effect of human resource policies on organizational commitment.

\section{Recommendations}

- Managers and owners should pay attention to the psychological contract, as it plays a major role in shaping and forming the mental image of workers about what will gain when they join it.

- Managers and owners should begin to manage the expectations of its members from the moment they apply to join the organization until the time they leave the organization through clear communication of policies.

- Managers and owners should keep all ways to prevent the psychological contract bleach.

- The need to support effective human resources policies, which increases the 
degree of commitment of employees and then improves the performance of employees, which is reflected in the overall performance and the achievement of the goals of the organizations.

\section{Conflicts of Interest}

The author declares no conflicts of interest regarding the publication of this paper.

\section{References}

[1] Rawya, H. (2014) A Strategic Approach to Human Resource Planning and Development. University House, Alexandria.

[2] Lv, Z. and Xu, T. (2016) Psychological Contract Breach, High-Performance Work System and Engagement: The Mediated Effect of Person-Organization Fit. The International Journal of Human Resource Management, 29, 1-28.

[3] Aries, S. and Miradipta, R. (2013) Analysis of the Effect of Attitude toward Work, Organizational Commitment, and Job Satisfaction, on Job Performance, (Case Study in Electronic Company). European Journal of Business and Social Sciences, 1 , 15-24. https://doi.org/10.9744/jti.15.1.13-24

[4] Bellou, V. (2007) Shaping Psychological Contracts in the Public and Private Sectors: A Human Resources Management Perspective. International Public Management Journal, 10, 327-349. https://doi.org/10.1080/10967490701515515

[5] Restubog, S.L.D., Zagenczyk, T.J., Bordia, P., Bordia, S. and Chapman, G.J. (2015) "If You Wrong Us, Shall We Not Revenge? Moderating Roles of Self-Control and Perceived Aggressive Work Culture in Predicting Responses to Psychological Contract Breach. Journal of Management, 41, 1132-1154.

https://doi.org/10.1177/0149206312443557

[6] Antony, J. (2013) The Influence of Emotional Intelligence on Organizational Commitment and Organizational Citizenship Behavior. International Journal of Social Science and Interdisciplinary Research, 2, 11-116.

[7] Adekola, B. (2012) The Impact of Organizational Commitment on Job Satisfaction: A Study of Employees at Nigerian Universities. International Journal of Human Resource Studies, 2, 17 p. https://doi.org/10.5296/ijhrs.v2i2.1740

[8] Loan, Le. (2020) The Influence of Organizational Commitment on Employees' Job Performance: The Mediating Role of Job Satisfaction. Management Science Letters, 10, 3308-3312. https://doi.org/10.5267/j.msl.2020.6.007

[9] Abdel-Rahman, T. (2005) Strategic Management. Jordanian Professional Expertise Center, Cairo.

[10] Al-Tabouli Al-Mabrouk, I.A. (2017) The Impact of Human Resources Management Policies on Employee Performance, Organizational Commitment as a Mediating Variable: An Applied Study on Al-Jumhuriya Bank Libya. College of Leadership and Management, University of Islamic Sciences Malaysia.

[11] Bakroun, A.M.I. (2019) The Type of Psychological Contract and Its Impact on Organizational Commitment: An Applied Study on the Palestinian Ministry of Local Government, Gaza, Business Administration at the Faculty of Economics and Administrative Sciences at the Islamic University, Gaza 2019. 